February - 2019

\title{
University Teachers and Open Educational Resources: Case Studies from Latin America
}

\author{
Virginia Rodés ${ }^{1}$, Adriana Gewerc-Barujel ${ }^{2}$, and Martín Llamas-Nistal ${ }^{3}$ \\ 1 Universidad de la República, Montevideo, Uruguay, ${ }^{2}$ Universidad de Santiago de Compostela, Santiago de Compostela, \\ Spain, ${ }^{3}$ Universidad de Vigo, Vigo, Spain
}

\begin{abstract}
The Open Education movement has made efforts to systematise experiences and to evaluate the adoption of Open Educational Resources (OER). However, OER adoption is not part of the prevailing paradigm in higher education, both at the global level and in Latin America. This paper describes results of a study that analysed the social representations regarding the development, use, and reuse of OER by university teachers in their pedagogical practices. We conducted a study of 12 cases from Latin American universities based on Grounded Theory. The results show that the use and reuse of OER lacks of public and institutional policies. The main agents are teachers organised in teams that support OER adoption. The reasons that encourage the creation of OER are mainly intrinsic, such as the pleasure derived from contributing and sharing, as well as external and related to professional development needs from the reflection on one's own educational practice. Educators consider it essential to evaluate the resources created so that they can be reused in continuous improvement processes. Commercial use and misappropriation of the works are two of the main tensions identified. The community factor of teaching guides most behaviours in OER adoption in educational institutions and is presented as an inherent part of the development and transformation of the curriculum.
\end{abstract}

Keywords: Open educational resources, university teachers, higher education, adoption, Latin America 


\section{Introduction}

Spanning over 20 years, the practice of creation, use, and open sharing of digital educational resources is far from being widespread in educational environments. Besides, Open Educational Resources (OER) adoption in the Global South is not yet fully understood (Hodgkinson-Williams \& Arinto, 2017). This paper presents the results of a study on OER adoption in Latin American (LATAM) Higher Education (HE) context. The study focuses on the social representations (Moscovici, 2006) regarding the development, use, and reuse of OER by university teachers in their pedagogical practices.

From an interpretative paradigm, we implemented a qualitative methodology on 12 cases from three public universities in three countries. Findings lead to identify three core categories: Institutional factors of the OER adoption; Attitudes and perceptions towards OER; and Practices of use, creation, and sharing of OER .

This paper is organised as follows: First, we introduce state of the arts on qualitative and mixed studies about the adoption of OER, then we explain the research methodology, and, finally, we address the results, discussion, and the most significant conclusions.

\section{State of the Arts}

Many efforts have been made to evaluate OER adoption, creating frameworks, and good practices. Despite the difficulties, OER dissemination has reached a maturity level, especially since the appearance of national and regional policies in the English-speaking north (Mulder, 2013; Stacey, 2013; de Langen, 2013; Falconer, Littlejohn, McGill, \& Beetham, 2016).

Thus, there is still a great imbalance in the Global South (Umar, Kodhandarama, \& Kanwar, 2013; Kanwar, Kodhandaraman, \& Umar, 2010; Cobo, 2013; Mtebe \& Raisamo, 2014), which includes linguistic barriers, digital gaps, closed educational systems, and lack of regional cooperation. However, Hodgkinson-Williams and Arinto, (2017) show that 51\% of academics from nine developing countries have used OER, with slightly different rates by region.

OER adoption in LATAM HE has been sparsely studied, showing early stages of adoption, mainly caused by the lack of visibility, mobilisation, and articulation of existing experiences (Inamorato, Cobo \& Costa, 2012; Abeywardena \& Westermann, 2017).

Numerous mixed and qualitative studies on the adoption of OER focus on teachers' perceptions and attitudes, enablers, and barriers (Allen \& Seaman, 2014; Annand, 2015; Annand \& Jensen, 2017; Arinto,; Belikov, 2016; Bossu \& Fountain, 2015; Cox, 2017; Cox \& Trotter, 2016; Hanley \& Bonilla, 2016; Harley, Lawrence, Acord, Dixson, \& University of California, 2009; Hassall \& Lewis, 2017; Hernández, 2014; Hodgkinson-Williams \& Arinto, 2017; Jung, Bauer, \& Heaps, 2017; Kaatrakoski, Littlejohn, \& Hood, 2016; McGreal, Anderson, \& Conrad, 2015; McGreal, Kinuthia, Marshall, Commonwealth of Learning, \& Athabasca University, 2013; McKerlich, Ives, \& McGreal, 2013; Mishra, 2017; Mitros \& Sun, 2014; Mtebe \& Raisamo, 2014; Shigeta et al., 2017; Stacey, 2013; Stagg, 2014; Toledo, 2017; Woodward, 2017).

Findings show that most university teachers are still not familiar with OER, and that these are not 
considered in the decision-making process regarding which educational materials will be used.

Several studies identify teachers as the main agents of the OER adoption decision-making process (Allen \& Seaman, 2014; Cox, 2017; D’Antoni, 2008; Rolfe, 2012) and the prevailing institutional culture as a relevant factor (Cox, 2017). Tensions related to educators' practice and OER are aligned with educators' practice, professional development, and wider societal factors in the educational field (Kaatrakoski et al., 2016).

Such findings allow us to identify institutional factors and teachers' agency as fundamental dimensions in the adoption of OER in HE. Within institutional factors, the most relevant are social culture (Cox, 2017), organisational structures and constraints (Falconer et al., 2016; Kaatrakoski et al., 2016; Pirkkalainen, Jokinen, \& Pawlowski, 2014), and institutional policies (Butcher, Kanwar, \& Uvalić-Trumbić, 2011; Conole, 2013; Cox, 2017; Cronin, 2018, 2018; D’Antoni, 2008; Glennie, Harley, Butcher, \& van Wyk, 2012; Inamorato Dos Santos et al., 2017; Kaatrakoski et al., 2016; Nkuyubwatsi, 2017).

Regarding policies, incentives, and academic promotion are enabling conditions for the adoption by academics (Annand \& Jensen, 2017; Conole, 2013; Hylén, 2006; McAndrew, Farrow, Elliott-Cirigottis, \& Law, 2012; Nkuyubwatsi, 2017). Nevertheless, recent studies show that policies can act as a motivating factor depending on the type of institutional culture it is embedded (Cox, 2017), and simultaneously lead to changes to both organisational and individual practice (Kaatrakoski et al., 2016).

Academics' practices of creating, sharing, and reusing OER are determined by motivation and desire or will to adopt OER (Cox, 2017; Reed, 2012; Rolfe, 2012), supportive environments (D'Antoni, 2008; Rolfe, 2012; Thakrar, Wolfenden, \& Zinn, 2009), and teachers' professional development (Hassall \& Lewis, 2017; Zhang \& Li, 2017), including digital literacies (Atenas, Havemann, \& Priego, 2015; Cronin, 2018; D’Antoni, 2008; Nkuyubwatsi, 2017), and copyright literacies (Anderson, 2011; Atenas et al., 2015; Rolfe, 2012; Secker \& Madjarevic, 2012). Petrides, Nguyen, Kargliani, and Jimes (2008) find visual and technical changes as the most prevalent reuse behaviours, and Falconer et al. (2016) identify major tensions between commercial use and open publication.

Teachers have identified barriers to OER adoption such as lack of enabling policies (Nkuyubwatsi, 2017), time (Allen \& Seaman, 2014; Rolfe, 2012), skills (Atenas et al., 2015; Rolfezhang, 2012), reward system (Rolfe, 2012), interest for pedagogical innovation among colleagues (Rolfe, 2012), confusion over copyright (Atenas, Havemann, \& Priego, 2014; Rolfe, 2012), technology access and support (Nkuyubwatsi, 2017; Rolfe, 2012), recognition (Atenas et al., 2014; Jhangiani, Pitt, Hendricks, Key, \& Lalonde, 2016; Nkuyubwatsi, 2017), self-confidence about the quality of their materials (Cox, 2017), OER awareness (Reed, 2012; Rolfe, 2012), availability of relevant and high-quality OER (Clements \& Pawlowski, 2012; Willems \& Bossu, 2012), and personal interest (Falconer et al., 2016; Reed, 2012; Rolfe, 2012).

National and institutional policies and strategies are enablers (Cox \& Trotter, 2016; Cronin, 2018; Lesko, 2013; Nkuyubwatsi, 2017), as well as incentives and promotion (Hylén, 2006; Nkuyubwatsi, 2017), extra time (Nkuyubwatsi, 2017), desire and volition (Cox \& Trotter, 2016), adequate resources (Thakrar et al., 2009), support for teachers (Thakrar et al., 2009), local culture (Cox \& Trotter, 2016; Thakrar et al., 2009), institutional practices (Cox \& Trotter, 2016; Thakrar et al., 2009), sustainable 
funding (Annand \& Jensen, 2017; Thakrar et al., 2009), infrastructure access (Cox \& Trotter, 2016; Kaatrakoski et al., 2016; Lesko, 2013; Nkuyubwatsi, 2017), legal permission (Cox \& Trotter, 2016), conceptual awareness (Cox \& Trotter, 2016; Rolfe, 2012), technical capacity (Cox \& Trotter, 2016), availability of educational resources (Cox \& Trotter, 2016; Hylén, 2006; Nkuyubwatsi, 2017), beliefs and values (Cox \& Trotter, 2016; Rolfe, 2012), and enhancement of individual and institutional reputations (Rolfe, 2012).

\section{Purpose of the Study}

This study aims at identifying the adoption dimensions of OER by university teachers in LATAM HE. The study deepens up in understanding social representations (Moscovici, 1979; Moscovici, 2006) of lecturers regarding OER in the context of their institutions and teaching practices.

The research questions that guided the study were:

- RQ1. What factors influence the adoption of OER among lecturers in LATAM universities?

- RQ2. How can these factors be addressed for enhancing the use and reuse of OER in LATAM universities?

\section{Methodology}

The study falls within the interpretive paradigm, where situated interpretations are used to understand social life. The methodological approach is qualitative, based on Grounded Theory (Glaser \& Strauss, 1967; Strauss \& Corbin, 1990; Miles \& Huberman, 1999; Charmaz, 2006).

Grounded theory both guides the research and the researcher, towards theoretical development (Charmaz \& Mitchell, 2001). What is constructed through this process is substantive theory, that is, theory that can be applied only to the area that is being analysed. Validation of the theoretical scheme with other actors, and the inclusion of new cases, people, or groups, can be developed.

\section{Participants}

We selected a population of university teachers who participated by sending their own educational resources to the Latin American Conference on Learning Technologies (LACLO) Learning Objects Contest, for the years 2012, 2013, and 2014.

The selection of this community is based on the understanding that participants are close enough to the creation and publication of digital educational resources to have the relevant experience within the subject of study. Although they may not necessarily be experts, they can be identified as representatives of the population of university teachers who create, use, and share digital educational resources.

On the database, a longitudinal quantitative study was conducted to characterise the population by pointing out some of its main demographic characteristics (Rodés, Pelerino, Gewerc, \& Llamas, 2016). The variables number, country, gender, discipline, and institution were analysed. 
The population studied included 283 individuals. Of the total, 120 were men (42\%) and 163 women (58\%; see Table 1).

Table 1

Population Distributed by Gender

\begin{tabular}{|l|r|r|}
\hline Gender & Number of participants & \% of participants \\
\hline Women & 163 & $58 \%$ \\
\hline Men & 120 & $42 \%$ \\
\hline Total & 283 & $100 \%$ \\
\hline
\end{tabular}

The research participants were from 10 countries, with the majority (84\%) located in Brazil (59.4\%), Colombia (13.8\%), and Venezuela (12.0\%), making them the highest participation group (HPG). In turn, Mexico, Chile, and Costa Rica in total account for almost 10\% of the participants, with shares of $3.9 \%, 3.2 \%$, and $2.8 \%$, respectively, placing these participants into the medium participation group (MPG). Finally, Cuba, Ecuador, Uruguay, and the USA together account for $5 \%$ of participants, with shares of $1.8 \%, 1.4 \%, 1.4 \%$, and $0.4 \%$ respectively. These are the low-participation group (LPG). Participants belong to 49 HE Institutions (HEIs): 22 from Brazil; 8 from Colombia; 4 from Cuba;. Venezuela, Mexico, and Chile have participants from three HEI each; and Costa Rica, Ecuador, Uruguay, and the USA have participants from one HEI each (see Table 2).

Table 2

Participants and Higher Education Institutions (HEIs) Per Country

\begin{tabular}{|l|r|r|r|}
\hline Countries & \% of participants & \multicolumn{1}{|l|}{ Group } & Number of HEIs \\
\hline Brazil & 59.4 & HPG & 22 \\
\hline Colombia & 13.8 & HPG & 8 \\
\hline Venezuela & 12.0 & HPG & 3 \\
\hline México & 3.9 & MPG & 3 \\
\hline Chile & 3.2 & MPG & 3 \\
\hline Costa Rica & 2.8 & MPG & 1 \\
\hline Cuba & 1.8 & LPG & 4 \\
\hline Ecuador & 1.4 & LPG & 1 \\
\hline Uruguay & 1.4 & LPG & 1 \\
\hline United States & 0.4 & LPG & 1 \\
\hline Total & 100.0 & & 49 \\
\hline
\end{tabular}

Participants come from 25 scientific disciplines that were grouped in three areas. The majority of participants were from Science and Technology (S\&T), while the two other discipline areas, Social Sciences and Arts (SS\&A) and Health Sciences (HS) had a lower, though significant, presence (see Table 3). 
Table 3

Population Distributed by Discipline Areas

\begin{tabular}{|l|r|r|}
\hline Area & Number of participants & \% of participants \\
\hline Science \& technology & 210 & $75 \%$ \\
\hline Social sciences \& arts & 59 & $20 \%$ \\
\hline Health sciences & 14 & $5 \%$ \\
\hline Total & 283 & $100 \%$ \\
\hline
\end{tabular}

The S\&T area includes disciplines such as computer sciences (37.81\%), educational computing (13.07\%), chemistry (7.77\%), physics (5.65\%), and maths (4.59\%), among others. The SS\&A area includes education (12.37\%), graphic design (2.83\%), language (2.12\%), and other. The last area, HS, includes nursing (2.12\%), medicine (1.7\%), and psychology (0.35\%), among others (see Table 4).

Table 4

Population Distributed by Disciplines

\begin{tabular}{|l|l|r|r|}
\hline Discipline & Area & Number of participants & \% of participants \\
\hline Computer sciences & S\&T & 107 & $37.81 \%$ \\
\hline Education informatics & S\&T & 37 & $13.07 \%$ \\
\hline Chemistry & S\&T & 22 & $7.77 \%$ \\
\hline Physics & S\&T & 16 & $5.65 \%$ \\
\hline Maths & S\&T & 13 & $4.59 \%$ \\
\hline Natural sciences & S\&T & 6 & $2.12 \%$ \\
\hline Seismology & S\&T & 3 & $1.06 \%$ \\
\hline Law & S\&A & 2 & $0.71 \%$ \\
\hline Agronomy & S\&T & 2 & $0.71 \%$ \\
\hline Statistics & S\&T & 2 & $0.71 \%$ \\
\hline Electrical engineering & S\&T & 1 & $0.35 \%$ \\
\hline Industrial engineering & S\&T & 1 & $0.35 \%$ \\
\hline Education & SS\&A & 35 & $12.37 \%$ \\
\hline Graphic design & SS\&A & 8 & $2.83 \%$ \\
\hline Language & SS\&A & 6 & $2.12 \%$ \\
\hline Economy & SS\&A & 3 & $1.06 \%$ \\
\hline Communication & SS\&A & 2 & $0.71 \%$ \\
\hline Administration & SS\&A & 1 & $0.35 \%$ \\
\hline Marketing & SS\&A & 1 & $0.35 \%$ \\
\hline Tourism & SS\&A & 1 & $0.35 \%$ \\
\hline Nursing & HS & 6 & $2.12 \%$ \\
\hline Medicine & HS & 5 & $1.77 \%$ \\
\hline Psychology & HS & 1 & $0.35 \%$ \\
\hline Dentistry & HS & 1 & $0.35 \%$ \\
\hline Speech Therapy & HS & 1 & $0.35 \%$ \\
\hline Total & & 283 & $100.00 \%$ \\
\hline
\end{tabular}

As can be seen, the wide territorial, cultural, and institutional coverage is offered by the LACLO community, allowing us to access a wide and diverse range of individuals. This provides the variability and comparability elements required for the theoretical sampling process that is fundamental for the methodology chosen. 


\section{Theoretical Sampling}

The aim of theoretical sampling is to compare events, incidents, or situations, to determine how a category can differ in terms of its properties and dimensions.

The participants were puposefully selected to maximise the differences between comparison groups, established by country, institution, disciplines, gender, and communities or work teams. Therefore, the dataset was designed as follows: a country from each group according to the degree of participation classification (high, medium, low) presented above. We selected Venezuela, Costa Rica, and Uruguay to have good territorial coverage of the Caribbean and the northern and southern regions of LATAM. Universidad Central de Venezuela (UCV),Universidad Estatal a Distancia de Costa Rica (UNED), and Universidad de la República (UDELAR), respectively. They are three public universities, with different characteristics regarding teaching modalities (distance education at UNED, mixed education at UCV, and face-to-face education at UDELAR). Twelve individuals were selected, four per university, considering variability regarding gender and areas of knowledge. From UCV, Venezuela, two men (V3 and V4) and two women (V1 and V2) were selected, who are teachers in the area of science and technology (computer science, physics, and chemistry); from UNED, Costa Rica, all were female teachers (CR1, CR2, CR3, and CR4), one from the area of science and technology (computer science) and three from the social and arts fields (education, tourism, and design); from UDELAR, Uruguay, we selected three women ( $\mathrm{U}_{2}, \mathrm{U}_{3}$, and $\mathrm{U}_{4}$ ) and one man (U1), a lecturer from the science and technology area (biology), two from the social and arts field (economics, communication), and one from healthcare (nursing).

\section{Data Collection}

We chose an open thematic interview to identify attitudes and practices regarding open educational resources.

The interviews were conducted between November 2015 and September 2016 using Google Hangouts live, which allowed us to make video calls and to record them automatically on YouTube. Between two and three interviews were conducted with each subject, lasting between $40 \mathrm{~min}$ and $1 \mathrm{~h} 20 \mathrm{~min}$ each. Over 24 hours of recordings were obtained.

\section{Data Analysis}

To perform the analysis we transcribed the interviews and then studied the resulting texts with the qualitative data analysis software Maxqda. The first stage of the analysis was coding the data, an analytical process through which data is fragmented, conceptualised, and integrated as theory through successive comparison processes (Strauss \& Corbin, 1990). The analysis led to developing 500 codes and identifying 3,547 text segments from the interviews that were identified through open codification-focusing on the main idea and not on pre-established dimensions.

The analysis results allowed us to identify three categories: 1) institutional components of OER adoption; 2) practices of use, creation, and sharing OER; and 3) knowledge, attitudes, and perceptions towards OER. 


\section{Results}

\section{Institutional Components of OER Adoption}

Policies. The results showcase the shortage of institutional policies to promote the development and adoption of OER in LATAM universities. Although some policies have been implemented, these are individual and contradictory initiatives, linked to schools, institutes, or faculties, and their adoption does not seem to be established or standardized. (In this section, supporting quotations for these findings are linked to the bracketed numbers.) [1] [2]

Nor are there any references to specific funding or incentive policies for OER creation. However, we must consider the opinion of teachers regarding the fact that the open sharing of educational resources would be part of their current salary. Therefore, it would not be right to expect higher remuneration on account of copyright, which is a strong attitude towards open publication [3], [4].

Teacher's agency. As there are no institutional policies, this depends on the initiative and willingness of teachers. This leads to several problems, mainly the invisibility and non-remuneration of the hours spent creating content, the value the institution places on research output at the expense of teaching outputs, and the lack of explicit reference in the curriculum linked to the development of educational resources [5], [6].

Organisational components. Despite the lack of specific policies, it is relevant to have work teams that facilitate and encourage the development of OER. These teams have organisational structures that reflect three clear models: 1) network, 2) hierarchical, and 3) centralised.

1. Model 1 includes teams located in schools and university services, coordinated by a central team, making up a network (UDELAR) [7].

2. Model 2 is a specialised board formed by departments, with a hierarchical and institutionalised structure (UNED) [8].

3. Model 3, which is centralised, includes lecturers coordinated by another lecturer who works as a techno-pedagogical advisor. The advisor works for the school level and acts as a leader. The lecturers do not work together, and only work with the leader The strategies are not at a central level, since the model includes students OER development practices (UCV) [9].

Workflow and methods for the creation of OER are similar for UCV and UDELAR, as they stem from the joint and collaborative development by teachers and experts within initiatives connected to teaching needs and problems [10] [11].

In UNED, we identified a structured, standardised, and planned work method to produce resources, based on the work of content experts, instructional designers, and graphic designers, in addition to a connection with distance education [12].

All the work teams studied have a member who becomes the leader and whom others recognise as a source of reference and initiatives in the field of OER. The academic structures include teams that manage VLEs, libraries, and editorial committees. 


\section{Practices of Use, Creation, and Sharing of Open Educational Resources}

Reasons that drive the creation of OER. We identified the following reasons driving the creation of educational resources in the respondents' discourse: how widespread classrooms are; distance education; students' academic paths (high school-university transition and graduation); the demand for making teaching methodologies more active; use of digital technologies in education; personalisation of learning; motivating students; theory-practice relationship; practice, experimentation, and simulation; students' need to have a good command of scientific language; support to students so they develop specific expertise; and encouraging reflexivity and critical thinking [13], [14], [15].

Process flow of creation and reuse of OER. The creation of educational resources begins, for all respondents, with a search for existing resources on the topic in which they are working. This search focuses on updating the educational resources created by them (with additions, improvements, or adaptation of material already created) or resources created by colleagues. They reuse their own resources and work in successive stages to validate, review, and improve them. They relate these continuous improvement processes of educational resources to the reflection and transformation of one's own educational practices [16], [17].

Within these validation processes, they assess various aspects of educational resources: multimedia and digital design, content, compliance with learning objectives, and their contribution to academic performance.

The review process gives rise to changes in formats and media, within the process of integration of technologies to education.

Within reuse, there is an emerging concept: the so-called "inspiration," which refers to the process of browsing and searching for ideas that inspire new creations of their own. This emerging concept is close to copying, and includes research on the state-of-the-art, the educational use of content not specifically designed for educational use, the development of lists and content curation, and adaptation of existing resources. The concept of inspiration is especially relevant in the flow of the respondents' discourse to the topic of licensing of works [18], [19].

\section{Attitudes and Perceptions Towards OER}

Attitudes towards open authorship and publishing. There is wide knowledge about the potential of educational and research work when it is openly published. A relevant finding is that they relate this work to the characteristics and mission of public universities in LATAM [20], [21] .

Regarding the use of open licenses, most respondents mention Creative Commons as usual practice, as well as attribution to the authors whose work is reused or cited. However, knowledge about open licenses is not homogeneous, and in some cases, there is a lack of general operational knowledge the copyright and open licensing [22], [23].

All respondents mention authorship attribution as a requirement for sharing educational resources. They agree that licensed resources must be shared in the same way, and there is evidence of a broad rejection of the use of licenses that allow derivative works to be marketed. Commercial use is linked with the need to monitor the balance between creation and consumption of educational resources, in 
particular between institutions. In addition, they link the licensing that allows for its commercial use with problems related to the globalisation and privatisation of higher education and the fear of indiscriminate appropriation of the resources developed by them [24].

They also discuss about attitudes to be promoted in the areas in which material is shared, particularly regarding caring for resources, rejecting copyright infringement and for-profit use. Another emerging and significant aspect is the requirement to monitor and approve modifications.

Regarding authorship practices, there are several emerging models. First, individual authorship, according to which the work belongs to the teacher that created it. A second model acknowledges the role of the university within which the work was produced. Here, authorship would be shared between the teacher and the university. The third model integrates the two above, and includes the relevance of other roles that participate in the creation of the work: graphic designers, educators, content specialists, etc. This points to a model of collaborative or collective authorship.

Enablers for OER adoption. Pleasure and willingness to contribute are the first reasons mentioned for adopting open creation and publication models. The second reason is the promotion of professionalisation and academic development associated with a teaching career, regarding concepts such as recognition, internationalisation, and visibility.

Willingness to share comes in third in order of relevance, and respondents link it to other concepts such as reuse, utility, quality of content, openness, use, and comparison.

Other relevant reasons identified were socialising knowledge, collaborating, making other people's work easier, helping others, collaborative work, and support teaching. These ideas appear linked to concepts such as facilitating students' access, motivating students, and promoting knowledge creation.

The creation of communities (establishing links, exchanging experiences, and receiving contributions from others) is a motivation that appears in their discourse, though not significantly. The same happens with the improvement and transformation of practices (associated to concepts such as change, analysis, and reflection). Though less frequently, there are reasons related to catering to the needs of the digital society, multidisciplinarity, being a way of life, or a duty. Remuneration is the least relevant aspect in the list of motivations for adopting open publishing models.

Perceived barriers for OER adoption. As identified in the interviews, the main barrier to the adoption of open publishing is the lack of understanding regarding copyright, as well as the fear of appropriating others' works. The following aspect in order of relevance is the time it takes to search for, reuse, and create educational resources. The reference made to the quality of the works and the conditions that would determine the "publishability" of resources is also relevant; these are works designed, in principle, to support teaching, so they feel a fear of exposure. The lack of training and knowledge on OER are also barriers, as well as the lack of recognition and of institutional support. Other barriers found less frequently are problems in the searching processes, and finally, localisation and adaptation of educational resources to educational contexts and situations.

\section{Discussion}

This study identifies dimensions of the adoption of OER in higher education in Latin America. 
Working in three countries, with 12 cases including respondents from three public universities, we aimed to contribute to the studies on adoption conducted within the Open Education movement in a variety of contexts and regions.

Our research contributes to the development of substantive theory, identifying practices and modalities followed by university teachers for creating, publishing, sharing, and reusing educational resources, as well as the inclusion of OER philosophy in these processes.

First, it contributes to the study of the barriers and motivations involved in the adoption of OER in university teaching practices, including the Latin American perspective, allowing for additional comparisons across the vast corpus of existing research at an international level on the subject.

The results are consistent with research conducted by Allen and Seaman (2014) and Hilton (2016). Not all the cases studied reflect a wide knowledge of OER as a concept, knowledge of open licensing systems, or the use of OER repositories for searches. However, in relation to perceptions of, and attitudes toward, open publication and sharing, these findings showcase a general willingness to adopt open publishing models. Therefore the adoption of OER appears to be encouraged in university education (See also Nkuyubwatsi, 2017; Cox, 2017; Reed, 2012; Rolfe, 2012).

This study has identified the role of decision-making as key for teachers regarding the development of educational resources, which is consistent with previous findings (See Allen \& Seaman, 2014; Cox, 2017; D'Antoni, 2008; Rolfe, 2012). Given the lack of regulation and systematic and widespread action frameworks, both the creation of educational resources and publication procedures depend on the will and decision of the faculty (Cox, 2017; Reed, 2012; Rolfe, 2012). Therefore, faculty empowerment is essential for the adoption of open publication practices.

The barriers identified in our study are also consistent with those surveyed in the literature, such as enabling policies (Nkuyubwatsi, 2017), time (Allen \& Seaman, 2014; Rolfe, 2012), skills (Atenas et al., 2015; Rolfe, 2012), confusion over copyright (Atenas et al., 2014; Rolfe, 2012), recognition (Atenas et al., 2014; Jhangiani et al., 2016; Nkuyubwatsi, 2017), self-confidence about the quality of their materials (Cox, 2017), and the fear of exposure, as the most prevalent.

Our study showcases the links between the educators' experiences of online teaching and the adoption of OER, which was also identified in Zhang and Li (2017). This can be seen in both the origins and formation of work groups, and in the close connection between the development and adaptation of teaching resources into digital formats, as a way to embed technologies in university teaching.

The findings on reuse practices are relevant as well because they allow us to observe the processes of searching and reusing as naturalised strategies that are part of the development of educational resources, in context with availability to technology. Consistent with Petrides et al. (2008), we found that the digitisation of pre-existing materials was one of the versioning practices, but not the only nor the most prevalent one.

The emerging concept of "inspiration" is another vector identified for the adoption of the OER philosophy, as long as promotion and training strategies are developed to empower teachers with essential information on open source licensing, OER repositories and good versioning practices.

Commercial use and misappropriation of the works is one of the main tensions identified in our study, 
similar to the findings of Falconer et al. (2016). As in Cox and Trotter (2016) and Rolfe (2012), core motivation is one of the factors for contributing and sharing, which is typical of academic communities focused on the common good. The educational communities studied follow an altruistic philosophy that includes the traditions and missions of the free, co-governed public universities in Latin America, showing the impact of institutional culture. These traditions collide with practices of misappropriation, imbalances between creation and consumption in the privatisation of education and the potential for-profit use of the works. However, contrary to numerous studies (e.g., Annand \& Jensen, 2017; Conole, 2013; Hylén, 2006; McAndrew et al., 2012; Nkuyubwatsi, 2017), a very relevant finding was identifying the creation of teaching resources as part of the tasks already compensated through an academics' salary, and the use of this argument as a basis for the adoption of open publication practices that promote the dissemination of knowledge as part of the social function of their teaching role and of the Latin American universities'social missions.

\section{Conclusions}

Regarding the factors influencing the adoption of OER among lecturers in LATAM universities, the results of this study show that the creation, use, and reuse of OER in Latin American HEIs requires supportive institutional policies to be improved. However, a significant number of communities and work teams support their adoption. The collaborative component is an interface between the teaching staff and the institution allowing to overcome the absence of institutional policies, favoring the adoption of OER.

We identified a series of vectors for the adoption, showing great potential for the design of widespread and coordinated strategies and policies that promote the visibility, articulation, and consolidation of actions in OER for Latin America, in particular from the public universities and as part of its egalitarian tradition and mission .

Among the barriers to the adoption of OER, the lack of knowledge in copyright, issues related to the quality of works, and fear of exposure, are the findings that may guide the design of strategies for dissemination and training, empowering teachers with the necessary knowledge to act with confidence in the contexts of open digital publication.

The reasons that have driven the creation of OER are mainly intrinsic factors, such as the pleasure of contributing and sharing, and professional development from reflecting on their own practice, as well as external demands. It is here that it becomes essential to evaluate the resources created so that they can be reused for continuous improvement processes .

The community factor of teaching guides most behaviours in educational institutions and is presented as an inherent part of the development and transformation of the curriculum . In that sense, any technological tool and methodological framework around OER, in particular those linked to the development of educational repositories, should integrate the sharing and collaborative planning of activities and training courses within the creation of educational communities, allowing for features such as version tracking and tracing, collaborative creation, collaborative evaluation, among others. 


\section{Acknowledgment}

This research was supported in part by: Red Iberoamericana para la Usabilidad de Repositorios Educativos , Red 513RTo471 (RIURE); Interdisciplinary Space, Sectoral Commission of Education, and Sectoral Commission of Scientific Research, Universidad de la República. 


\section{References}

Abeywardena, I., \& Westermann, W. (2017). Latin America and Caribbean regional consultation on open educational resources OER for inclusive and equitable quality education: From commitment to action. Sao Paulo, Brazil: Commonwealth of Learning. Retrieved from http://rcoer.col.org/uploads/2/2/8/4/2284118o/lac_rcoer_report_final.pdf

Allen, I. E., \& Seaman, J. (2014). Opening the curriculum: Open Educational resources in US higher education. Babson Survey Research Group.

Anderson, L. (2011). DELILA - Embedding digital and information literacy OERs into the PG Cert. Journal of Information Literacy, 5(1). https://doi.org/10.11645/5.1.1611

Annand, D. (2015). Developing a sustainable financial model in higher education for open educational resources. The International Review of Research in Open and Distributed Learning, 16(5). https://doi.org/10.19173/irrodl.v16i5.2133

Annand, D., \& Jensen, T. (2017). Incentivizing the production and use of open educational resources in higher education institutions. The International Review of Research in Open and Distributed Learning, 18(4). Retrieved from http://www.irrodl.org/index.php/irrodl/article/view/3009

Arinto, P., Hodgkinson-Williams, C., \& Trotter, H. (2017). OER and OEP in the global south: Implications and recommendations for social inclusion. In Adoption and impact of OER in the Global South (pp. 577-592). Cape Town \& Ottawa: African Minds, International Development Research Centre \& Research on Open Educational Resources. https://doi.org/10.5281/zenodo.1094869

Atenas, J., Havemann, L., \& Priego, E. (2014). Opening teaching landscapes: The importance of quality assurance in the delivery of open educational resources. Open Praxis, 6(1), 29-43. doi:http://dx.doi.org/10.5944/openpraxis.6.1.81

Atenas, J., Havemann, L., \& Priego, E. (2015). Open data as open educational resources: Towards transversal skills and global citizenship. Open Praxis, 7(4), 377-389.

doi:http://dx.doi.org/10.5944/openpraxis.7.4.233

Belikov, O., \& Bodily, R. (2016). Incentives and barriers to OER adoption: A qualitative analysis of faculty perceptions. Open Praxis, 8(3), 235-246.

doi:http://dx.doi.org/10.5944/openpraxis.8.3.308

Bossu, C., \& Fountain, W. (2015). Capacity-building in open education: An Australian approach. Open Praxis, 7(2), 123-132. https://doi.org/10.5944/openpraxis.7.2.197

Butcher, N., Kanwar, A., \& Uvalić-Trumbić, S. (2011). A basic guide to open educational resources (OER). Vancouver; Paris: Commonwealth of Learning ; UNESCO. Charmaz, K. (2006). Constructing grounded theory. London; Thousand Oaks, CA: Sage Publications.

Charmaz, K., \& Mitchell, R. G. (2001). Grounded theory in ethnography. In P. Atkinson, A. Coffey, S. 
Delamont, J. Lofland, \& L. Lofland, Handbook of ethnography (pp. 160-174). United Kingdom: SAGE Publications Ltd. https://doi.org/10.4135/9781848608337.n11

Clements, K. I., \& Pawlowski, J. M. (2012). User-oriented quality for OER: Understanding teachers' views on re-use, quality, and trust: User-oriented quality for OER. Journal of Computer Assisted Learning, 28(1), 4-14. https://doi.org/10.1111/j.1365-2729.2011.00450.x

Cobo, C. (2013). Exploration of open educational resources in non-English speaking communities. The International Review of Research in Open and Distributed Learning, 14(2), 106-128. https://doi.org/10.19173/irrodl.v14i2.1493

Conole, G. (2013). Designing for Learning in an Open World. New York: Springer-Verlag. Retrieved from https://www.springer.com/gb/book/9781441985163

Cox, G., \& Trotter, H. (2016). Institutional culture and OER policy: How structure, culture, and agency mediate OER policy potential in South African universities. International Review of Research in Open and Distributed Learning, 17(5), 147-164. https://doi.org/10.19173/irrodl.v17i5.2523

Cox, G., \& Trotter, H. (2017). Factors shaping lecturers' adoption of OER at three South African universities. In adoption and impact of OER in the global south (pp. 287-347). Cape Town \& Ottawa: African Minds, International Development Research Centre \& Research on Open Educational Resources. https://doi.org/10.5281/zenodo.1094852

Cronin, C. (2018). Openness and praxis: A situated study of academic staff meaning-making and decision-making with respect to openness and use of open educational practices in higher education (Doctoral disstertation, NUI Galway, Ireland). Retrieved from https://aran.library.nuigalway.ie/handle/10379/7276

D’Antoni, S. (2008). Open educational resources the way forward, deliberations of an international community of interest. Retrieved from https://unesdoc.unesco.org/ark:/48223/pfooo0157987

de Langen, F. H. T. (2013). Strategies for Sustainable Business Models for Open Educational Resources. International Review of Research in Open and Distance Learning, 14(2), 53-66. https://doi.org/10.19173/irrodl.v14i2.1533

Falconer, I., Littlejohn, A., McGill, L., \& Beetham, H. (2016). Motives and tensions in the release of open educational resources: The UKOER program. Australasian Journal of Educational Technology, 32(4). https://doi.org/10.14742/ajet.2258

Glaser, B. G., \& Strauss, A. L. (1967). The discovery of grounded theory: Strategies for qualitative research. New Brunswick: Aldine.

Glennie, J., Harley, K., Butcher, N., \& van Wyk, T. (2012). Open Educational resources and change in higher education: Reflections from practice. Commonwealth of Learning (COL). Retrieved from http://oasis.col.org/handle/11599/80

Hanley, L. F., \& Bonilla, D. (2016). Atolls, Islands, and Archipelagos: The California OER council and 
the new landscape for open education in California. Open Praxis, 8(2), 131-142. http://dx.doi.org/10.5944/openpraxis.8.2.284

Harley, D., Lawrence, S., Acord, S. K., \& Dixson, J. (2009). Affordable and open textbooks: An exploratory study of faculty attitudes. California Journal of Politics and Policy, 2(1), 1-28. https://doi.org/10.5070/P2D6oT

Hassall, C., \& Lewis, D. I. (2017). Institutional and technological barriers to the use of open educational resources (OERs) in physiology and medical education. Advances in Physiology Education, 41(1), 77-81. https://doi.org/10.1152/advan.00171.2016

Hernández, A. T. (2014). Public expenditure in education in Latin America. Recommendations to serve the purposes of the Paris Open Educational Resources Declaration. Open Praxis, 6(2), 103-113. https://doi.org/10.5944/openpraxis.6.2.119

Hodgkinson-Williams, C., \& Arinto, P. B. (Eds.). (2017). Adoption and impact of OER in the Global South. Cape Town: African Minds Publishers.

Hylén, J. (2006). Open educational resources: Opportunities and challenges. Proceedings of Open Education, 49-63.

Inamorato, A., Cobo, C., \& Costa, C. (2012). Open educational resources: Cases from Latin America and Europe in higher education (SSRN Scholarly Paper No. ID 2193109). Rochester, NY: Social Science Research Network. Retrieved from https://papers.ssrn.com/abstract=2193109

Inamorato Dos Santos, A., Nascimbeni, F., Bacsich, P., Atenas, J., Aceto, S., Burgos, D., \& Punie, Y. (2017). Policy approaches to open education - case studies from 28 EU member states (OpenEdu Policies) (EUR - Scientific and Technical Research Reports). Publications Office of the European Union. https://doi.org/10.2760/283135

Jhangiani, R. S., Pitt, R., Hendricks, C., Key, J., \& Lalonde, C. (2016). Exploring faculty use of open educational resources at British Columbia post-secondary institutions. BCcampus Research Report. Victoria, BC: BCcampus.

Jung, E., Bauer, C., \& Heaps, A. (2017). Higher Education faculty perceptions of open textbook adoption. International Review of Research in Open and Distributed Learning, 18(4), 123141. https://doi.org/10.19173/irrodl.v18i4.3120

Kaatrakoski, H., Littlejohn, A., \& Hood, N. (2017). Learning challenges in higher education: an analysis of contradictions within Open Educational Practice. Higher Education, 74(4), 599615. https://doi.org/10.1007/s10734-016-0067-z

Kanwar, A., Kodhandaraman, B., \& Umar, A. (2010). Toward sustainable open education resources: A perspective from the Global South. American Journal of Distance Education, 24(2), 65-80. https://doi.org/10.1080/08923641003696588

Lesko, I. (2013). The use and production of OER \& OCW in teaching in South African higher education institutions (Case Study). Open Praxis, 5(2), 103-121. 
http://dx.doi.org/10.5944/openpraxis.5.2.52

McAndrew, P., Farrow, R., Elliott-Cirigottis, G., \& Law, P. (2012). Learning the lessons of openness. Journal of Interactive Media in Education, 2012(2). https://doi.org/10.5334/2012-10

McGreal, R., Anderson, T., \& Conrad, D. (2015). Open educational resources in Canada 2015. International Review of Research in Open and Distributed Learning, 16(5), 161-175. https://doi.org/10.19173/irrodl.v16i5.2404

McGreal, R., Kinuthia, W., \& Marshall, S. (Ed.) (2013). Open educational resources: Innovation, research and practice. Vancouver: Commonwealth of Learning and Athabasca University.

McKerlich, R. C., Ives, C., \& McGreal, R. (2013). Measuring use and creation of open educational resources in higher education. The International Review of Research in Open and Distributed Learning, 14(4). Retrieved from http://www.irrodl.org/index.php/irrodl/article/view/1573

Miles, M. B., \& Huberman, A. M. (1999). Qualitative data analysis. Thousand Oaks: Sage Publications.

Mishra, S. (2017). Open educational resources: Removing barriers from within. Distance Education, 38(3), 369-380. https://doi.org/10.1080/01587919.2017.1369350

Mitros, P., \& Sun, F. (2014). Creating educational resources at scale. In 2014 IEEE 14th International Conference on Advanced Learning Technologies (pp. 16-18). https://doi.org/10.1109/ICALT.2014.15

Moscovici, S. (1979). El psicoanálisis, su imagen y su público. [Psicoanalysis, its image and public.] Buenos Aires: Huemul.

Moscovici, S. (2006). Notes towards a description of Social Representations. European Journal of Social Psychology, 18(3), 211-250. https://doi.org/10.1002/ejsp.2420180303

Mtebe, J. S., \& Raisamo, R. (2014). Investigating perceived barriers to the use of open educational resources in higher education in Tanzania. The International Review of Research in Open and Distributed Learning, 15(2). https://doi.org/10.19173/irrodl.v15i2.1803

Mulder, F. (2013). The LOGIC of National Policies and Strategies for Open Educational Resources. International Review of Research in Open and Distance Learning, 14(2), 96-105. https://doi.org/10.19173/irrodl.v14i2.1536

Nkuyubwatsi, B. (2017). Willingness to engage in open educational practices among academics in Rwandan public higher education and responsive actions. Journal of Learning for Development - JL4D, 4(3). Retrieved from http://www.jl4d.org/index.php/ejl4d/article/view/223

Petrides, L., Nguyen, L., Kargliani, A., \& Jimes, C. (2008). Open educational resources: Inquiring into author reuse behaviors. In P. Dillenbourg \& M. Specht (Eds.), Times of convergence. 
Technologies across learning contexts (Vol. 5192, pp. 344-353). Berlin, Heidelberg: Springer Berlin Heidelberg. https://doi.org/10.1007/978-3-540-87605-2 39

Pirkkalainen, H., Jokinen, J. P. P., \& Pawlowski, J. M. (2014). Understanding social OER environments \#x2014: A quantitative study on factors influencing the motivation to share and collaborate. IEEE Transactions on Learning Technologies, 7(4), 388-400. https://doi.org/10.1109/TLT.2014.2323970

Reed, P. (2012). Awareness, attitudes and participation of teaching staff towards the open content movement in one university. Research in Learning Technology, 20. https://doi.org/10.3402/rlt.v20io.18520

Rodés Paragarino, V., Pelerino Francolino, F., Gewerc Barujel, Adriana, A., \& Llamas Nistal, M. (2016). A characterization of users of digital educational resources repositories the case of the Latin American Community of Learning Objects \#x2014; LACLO. In 2016 XI Latin American Conference on Learning Objects and Technology (LACLO; pp. 1-8). https://doi.org/10.1109/LACLO.2016.7751793

Rolfe, V. (2012). Open Educational Resources: Staff Attitudes and Awareness. Research in Learning Technology, 2o(1). Retrieved from http://search.ebscohost.com/login.aspx?direct=true\&db=eric\&AN=EJ973804\&lang=es\&site $=$ ehost-live

Secker, J., \& Madjarevic, N. (2012). Sharing information literacy resources as open educational resources: lessons from DELILA. SCONUL Focus, 55. 14-17. Retrieved from https://www.sconul.ac.uk/sites/default/files/documents/5.pdf

Shigeta, K., Koizumi, M., Sakai, H., Tsuji, Y., Inaba, R., \& Hiraoka, N. (2017). A survey of the awareness, offering, and adoption of OERs and MOOCs in Japan. Open Praxis, 9(2), 195-206. http://dx.doi.org/10.5944/openpraxis.9.2.568

Stacey, P. (2013). Government support for open educational resources: Policy, funding, and strategies. International Review of Research in Open and Distance Learning, 14(2), 67-80. https://doi.org/10.19173/irrodl.v14i2.1537

Stagg, A. (2014). La adopción de los recursos educativos abiertos: un continuo de práctica abierta. [OER adoption: a continuum for practice] RUSC. Universities and Knowledge Society Journal, 11(3), 161-176. http://dx.doi.org/10.7238/rusc.v11i3.2102

Strauss, A. L., \& Corbin, J. M. (1990). Basics of qualitative research: Grounded theory procedures and techniques. Newbury Park, CA: Sage Publications.

Thakrar, J., Wolfenden, F., \& Zinn, D. (2009). Harnessing open educational resources to the challenges of teacher education in Sub-Saharan Africa. The International Review of Research in Open and Distributed Learning, 10(4). https://doi.org/10.19173/irrodl.v10i4.705】

Toledo, A. (2017). Open access and OER in Latin America: A survey of the policy landscape in Chile, Colombia and Uruguay. In Adoption and impact of OER in the Global South (pp. 121-141). 
Cape Town \& Ottawa: African Minds, International Development Research Centre \& Research on Open Educational Resources. https://doi.org/10.5281/zenodo.1094840

Umar, A., Kodhandarama, B., \& Kanwar, A. (2013). Can open educational resources thrive in closed educational systems? Some reflections on OER in developing countries. In Commonwealth of Learning, Athabasca University (pp. 193-206). Retrieved from https://oerknowledgecloud.org/sites/oerknowledgecloud.org/files/pub PS OERIRP web.pdf\#page $=219$

Woodward, K. M. (2017). Building a path to college success: advocacy, discovery and OER adoption in emerging educational models. Journal of Library \& Information Services in Distance Learning, 11(1-2), 206-212. https://doi.org/10.1080/1533290X.2016.1232053

Zhang, M., \& Li, Y. (2017). Teaching experience on faculty members' perceptions about the attributes of open educational resources (OER). International Journal of Emerging Technologies (IJET), 12(4), 191-199 http://dx.doi.org/10.3991/ijet.v12io4.6638 